\title{
Field response of Colorado potato beetle to enantiomeric blends of CPB I aggregation pheromone
}

\author{
Thomas P. Kuhar $^{1 *}$, Erin M. Hitchner ${ }^{1}$, Roger R. Youngman ${ }^{1}$, Kenji Mori ${ }^{2}$, \\ Joseph C. Dickens ${ }^{3}$ \\ ${ }^{1}$ Department of Entomology, Virginia Tech, Blacksburg, USA; ${ }^{*}$ Corresponding Author: tkuhar@,vt.edu \\ ${ }^{2}$ Insect Pheromone and Traps Division, Fuji Flavor Co., Ltd., Tokyo, Japan \\ ${ }^{3}$ United States Department of Agriculture, Agriculture Research Service, Henry A. Wallace Beltsville Agricultural Research Center, \\ Plant Sciences Institute, Invasive Insect Biocontrol and Behavior Laboratory, Beltsville, USA
}

Received 4 September 2012; revised 17 October 2012; accepted 28 October 2012

\begin{abstract}
Colorado potato beetle, Leptinotarsa decemlineata, is attracted to (S)-3,7-dimethyl-2-oxooct-6-ene-1,3-diol [(S)-CPB I], a male-produced aggregation pheromone. Pitfall trap studies were conducted to assess the relative attraction of $L$. decemlineata adults to synthetic mixtures of the $(S)$ - and $(R)$-enantiomers of the pheromone. Of the following blends that were tested: 97\%(S):3\%(R), $87 \%(S): 13 \%(R), \quad 73 \%(S): 27 \%(R)$, and $50 \%(S): 50 \%(R)$ (racemic blend), only the blend containing $97 \%$ of the (S)-enantionmer was attractive in one of the experiments. Our results demonstrate that the behavioral response of the beetle to pheromone-baited pitfall traps is unsubstantial in general, and that enantiomeric blends containing $13 \%$ or more of the opposite $(R)$ enantiomer disrupt response to the pheromone. Any future research as well as integrated pest management strategies that incorporate CPB I as an aggregation pheromone should utilize blends containing more than $87 \%$ optical purity of the (S)-enantiomer of the pheromone.
\end{abstract}

Keywords: Leptinotarsa decemlineata; Chemical Ecology; Lures; Traps; Behavior

\section{INTRODUCTION}

The Colorado potato beetle (CPB), Leptinotarsa decemlineata Say (Coleoptera:Chrysomelidae), is a major pest in the United States and Europe, where adults and larvae can completely defoliate potato and eggplant resulting in substantial yield loss [1]. The insect has been notorious for developing resistance to insecticides [2,3], and alternative pest management strategies are frequently sought [1]. Moreover, there is need for effective monitoring tools for $L$. decemlineata particularly in areas that consider the pest a new invasive insect $[4,5]$.

Recently, a male-produced aggregation pheromone for $L$. decemlineata was identified as (S)-3, 7-dimethyl-2oxo-oct-6-ene-1, 3-diol [(S)-CPB I] [6]. The researchers were able to identify the aggregation pheromone by performing an antennectomy and topically applying juvenile hormone III, which resulted in a 200-fold increase in the production of the pheromone, enabling its identification. The pheromone has been shown to be attractive to $L$. decemlineata larvae [7] as well as male and female adults [6]. Kuhar et al. [8] demonstrated the attractiveness of (S)-CPB I in the field as well as its potential for integrated pest management of $L$. decemlineata. The beetle naturally produces optically pure (S)-CPB I pheromone [6]. Initial synthetic routes for (S)-CPB I of high purity have been complicated and expensive [9], and only recently has an economic synthesis been developed that would facilitate use of the optically active pheromone in the field [10]. Electroantennogram responses indicated that $L$. decemlineata antennal receptors for CPB I responded selectively to the (S)-enantiomer [6]. However, equal amounts of the racemate were found to evoke an intermediate response in $L$. decemlineata antennal receptors, perhaps indicative of receptors for the $(R)$-enantiomer. Behavioral tests utilizing an open Ytrack olfactometer found that both male and female $L$. decemlineata adults were attracted to the pure $(S)$-enantiomer, but showed no preference for the pure $(R)$-enantiomer or the racemate (50:50 blend) [6]. It is possible that a mixture containing predominately the $(S)$-enantiomer with small amounts of the inactive $(R)$-enantiomer might be active in the field. Such a blend of enantiomers would likely decrease the cost of synthesis while still providing a useful attractant for field use. The objectives 
of this study were to identify the field activity of various enantiomeric blends of the CPB I aggregation pheromone for catching $L$. decemlineata adults.

\section{MATERIALS AND METHODS}

\subsection{CPB I Pheromones}

CPB I pheromone enantiomers were synthesized as described by Mori and Tashiro [9]. Blends of enantiomers were prepared from $(S)$ - and $(R)$-3,7-dimethyl-2oxo-oct-6-ene-1,3-diol [(S)-CPB I and $(R)$-CPB I, respectively] by mixing the synthetic enantiomers previously dissolved in a 1:1 mixture of hexane and ethyl acetate. ( $S$ )-CPB I and $(R)$-CPB I were $96.5 \%$ and $96 \%$ optically pure, respectively (10). Blends were released from red rubber septa obtained from Fisher Scientific Co., Cat. No. 03-215-5. Prior to treatment, septa were washed several times in hexane. Individual septa were then treated with $50 \mu \mathrm{l}$ total of $10-\mu \mathrm{g} / \mu \mathrm{l}$ solutions of $(S)$ - and $(R)$-CPB I in 50\% hexane:50\% ethyl acetate to give 500 $\mu \mathrm{g}$ of CPB I enantiomers per septum. The solvent was allowed to evaporate prior to wrapping the septa individually in aluminum foil and placing them in plastic freezer bags in an ice chest for transport to the field. In order to estimate the percentage purity of the $(S)$-enantiomer required to elicit a behavioral response from $L$. decemlineata in the field, the following four blends of enantiomers were prepared and tested: $96.5 \%(S): 3.5 \%(R)$, which was the highest level of purity that we could obtain; the racemic blend $50 \%(S): 50 \%(R)$; and two intermediate ratios, $87 \%(S): 13 \%(R)$; and $73 \%(S): 27 \%(R)$. The solvent control consisted of $50 \mu$ l of a $50 \%$ hexane: $50 \%$ ethyl acetate solution applied to a septum as described above for the experimental treatments.

\subsection{Field Experiments}

Field experiments were conducted in summer of 2007 at the Virginia Tech Eastern Shore Agricultural Research
\& Extension Center in Painter, Virginia (USA). Four 0.01 hectare plots were cultivated to remove any weeds and create a level ground surface. In each of these four spatially-isolated locations, a 9-m diameter circle was laid out with a total of twelve pitfall trap stations situated equally around the circumference of the circle such that all stations were $4.5 \mathrm{~m}$ from the center of the circle (release point for insects), and $2.4 \mathrm{~m}$ from each other. Pitfall trap stations consisted of a $25-\mathrm{cm}$ long sheet of aluminum flashing placed vertically in the ground as a barrier and on both ends, an 11-cm diameter cup was buried flush to the ground. Pitfall cups were filled with water and $30 \mathrm{ml}$ of liquid soap detergent. A metal flag was placed between the two cups to mark the station location and to attach a rubber septum lure $40 \mathrm{~cm}$ above the soil surface.

For each of the four circular plots, every other pitfall trap station (station position numbers $2,4,6,8,10$, and 12) received a rubber septum with the designated ratio of the enantiomer, while the other six stations (odd-numbered stations) were controls and received a rubber septum treated with the solvent. Experiments were conducted on 12 and 20 June and 18 July. Immediately following each lure placement in the field, approximately 400 CPB adults were collected from a nearby potato field and released into the center of each plot. After $24 \mathrm{~h}$, traps were assessed and beetles were taken to the laboratory where they were sexed. Effect of pheromone treatment on catch of $L$. decemlineata was evaluated using a Student's t-test $(\mathrm{df}=5)$ at the $\mathrm{P}<0.05$ level of signifycance (Table 1).

\section{RESULTS}

The sex ratio of male to female beetles caught in pitfall traps was approximately $50 \%$, thus catches of both were combined for data analysis and reporting. Despite releasing $\sim 400 \mathrm{~L}$. decemlineata adults in the circular plot, pitfall trap catch was relatively low, ranging from an

Table 1. Mean \pm SE number of $L$. decemlineata adults caught per trap after three days in paired pitfall trap experiments $(n=6)$ with and without rubber septa lures containing various ratios of $(S)$ - and $(R)$-enantiomers of the CPB I aggregation pheromone, Painter, Virginia (USA) 2007.

\begin{tabular}{|c|c|c|c|c|c|c|}
\hline \multirow{2}{*}{$(S):(R)$ ratio } & \multicolumn{2}{|c|}{ Test 1 (12 June) } & \multicolumn{2}{|c|}{ Test 2 (20 June) } & \multicolumn{2}{|c|}{ Test 3 (18 July) } \\
\hline & Baited & Unbaited & Baited & Unbaited & Baited & Unbaited \\
\hline $50: 50$ & $3.5 \pm 0.8$ & $2.5 \pm 0.7$ & $2.2 \pm 0.6$ & $0.8 \pm 0.4$ & $2.0 \pm 1.2$ & $1.0 \pm 0.6$ \\
\hline $73: 27$ & $2.7 \pm 1.2$ & $1.8 \pm 1.2$ & $1.0 \pm 0.3$ & $0.5 \pm 0.2$ & $6.8 \pm 1.8$ & $5.7 \pm 2.4$ \\
\hline $87: 13$ & $3.5 \pm 0.5$ & $1.3 \pm 0.5$ & $1.7 \pm 0.9$ & $1.2 \pm 0.3$ & $2.7 \pm 1.4$ & $3.2 \pm 0.9$ \\
\hline $96.5: 3.5$ & $2.3 \pm 1.0^{*}$ & $0.3 \pm 0.2$ & $2.3 \pm 1.2$ & $1.5 \pm 0.5$ & $4.0 \pm 2.1$ & $2.3 \pm 0.5$ \\
\hline
\end{tabular}

${ }^{*}$ Source of variation significant based on Student's t-test at $\mathrm{P}<0.05$. 
average of 0.3 to 7.0 beetles per trap per $72 \mathrm{hr}$ across the three experiments. A statistical difference in trap catch was only recorded in the first experiment (12 June), where significantly more $L$. decemlineata were caught in the $96.5 \%(S): 3.5 \%(R)$ baited traps than unbaited traps $(\mathrm{t}$ $=2.71, \mathrm{df}=5 ; \mathrm{P}<0.0422)$. Although not significant, the trend was similar in the 20 June and 12 July experiments, which resulted in traps baited with $96.5 \%(S): 3.5 \%(R)$ catching roughly twice as many beetles as the unbaited traps when averaged across the three experiments. No significant differences in trap catch between baited and unbaited traps were observed for any of the other enantiomer ratios.

\section{DISCUSSION}

The proper enantiomeric ratio is often critical to the attractiveness of an insect pheromone [11-18]. Our research demonstrates the lack of attraction of adult CPB to the $(R)$-enantiomer and racemate blends of CPB I aggregation pheromone to $L$. decemlineata in the field. These results support lab observations previously reported by Dickens et al. [6]. In addition, although relatively pure 96.5(S):3.5(R) CPB I was moderately attracttive to $L$. decemlineata adults in the field, the numbers of beetles drawn to these baited traps was relatively minimal. Following the release of 400 beetles, an average of only 1 beetle was caught in each of the 97(S):3(R) baited traps. Thus, utilization of the pheromone for pest management purposes will likely involve a combination with other attractants such as plant volatiles [19], or in a trap crop strategy in which host volatiles are already present $[8,20]$.

\section{ACKNOWLEDGEMENTS}

We give special thanks to the staff at the Virginia Tech Eastern Shore Agricultural Research Center for their technical assistance with this research project.

\section{REFERENCES}

[1] Hare, J.D. (1990) Ecology and management of the Colorado potato beetle. Annual Review of Entomology, 35, 81-100. doi:10.1146/annurev.en.35.010190.000501

[2] Casagrande, R.A. (1987) The Colorado potato beetle: 125 years of mismanagement. Bulletin of the Entomological Society of America, 33, 142-150.

[3] Alyokhin, A., Baker, M., Mota-Sanchez, D., Dively, G. and Grafius, E. (2008) Colorado potato beetle resistance to insecticides. American Journal of Potato Research, 85, 395-413. doi:10.1007/s12230-008-9052-0

[4] Botha, J., Hardie, D. and Power, G. (2001) Colorado potato beetle Leptinotarsa decemlineata: Exotic threat to Western Australia. The Gov. Western Austr. Agriculture
Factsheet Online.

http://www.agric.wa.gov.au/content/pw/ins/pp/hort/fs009 $\underline{01 . p d f}$

[5] Zhang, H., Li, X., Wang, C.J. and Qiu, L.H. (2007) Advances in the researches on control and insecticide resistance in Leptinotarsa decemlineata. Chinese Bulletin of Entomology, 44, 496-500.

[6] Dickens, J.C., Oliver, J.E, Hollister, B., Davis, J.C. and Klun, J.A. (2002) Breaking a paradigm: Male-produced aggregation pheromone for the Colorado potato beetle. Journal of Experimental Biology, 205, 1925-1933.

[7] Hammock, J.A., Vinyard, B. and Dickens, J.C. (2007) Response to host plant odors and aggregation pheromone by larvae of the Colorado potato beetle on a servosphere. Arthropod-Plant Interactions, 1, 27-35. doi:10.1007/s11829-007-9005-4

[8] Kuhar, T.P., Mori, K. and Dickens, J.C. (2006) Potential of a synthetic aggregation pheromone for integrated pest management of Colorado potato beetle, Leptinotarsa decemlineata (Say). Agricultural and Forest Entomology, 8, 77-81. doi:10.1111/j.1461-9555.2006.00286.x

[9] Mori, K. and Tashiro, T. (2004) Useful reactions in modern pheromone synthesis. Current Organic Synthesis, 1, 11-29. doi:10.2174/1570179043485466

[10] Babu, B.N. and Chauhan, K.R. (2009) Enantioselective synthesis of (S)-3,7-dimethyl-2-oxo-6-octene-1,3-diol: A Colorado potato beetle pheromone. Tetrahedron Letters, 50, 66-67. doi:10.1016/j.tetlet.2008.10.092

[11] Klun, J.A., Chapman, O.L., Mattes, K.C., Wojtkowski, P.W., Beroza, M. and Sonnet, P.E. (1973) Insect sex pheromones: Minor amounts of opposite geometrical isomer critical to attraction. Science, 181, 661-663. doi:10.1126/science.181.4100.661

[12] Doolittle, R.E., Tumlinson, J.H., Proveaux, A.T. and Heath, R.R. (1979) Synthesis of the sex pheromone of the Japanese beetle. Journal of Chemical Ecology, 6, 15731581

[13] Borden, J.H. (1985) Aggregation pheromones. In: Kerkut, G.A. and Gilbert, L.I. Ed., Comprehensive Insect Physiology, Biochemistry, and Pharmacology, Pergamon Press, Oxford, 8, 257-258.

[14] Glover, T.J., Tang, X.H. and Roelofs, W.L. (1987) Sex pheromone blend discrimination by male moths form $E$ and $Z$ strains of European corn borer. Journal of Chemical Ecology, 13, 143-151. doi:10.1007/BF01020358

[15] Snow, J.W., Schwarz, M. and Klun, A.J. (1987) The attraction of the grape root borer, Vitacea polistiformis (Harris) (Lepidoptera: Sesiidae) to (E,Z)-2,13 octadecadienyl acetate and the effects of related isomers on attraction. Journal of Entomological Science, 22, 371-374.

[16] DuRant, J.A., Fescemyer, H.W., Mason, C.E. and Udayagiri, S. (1995) Effectiveness of four blends of European corn borer (Lepidoptera: Pyralidae) sex pheromone isomers at three locations in South Carolina. Journal of Agricultural Entomology, 12, 241-253.

[17] Bartels, D.W., Hutchison, W.D. and Udayagiri, S. (1997) Pheromone trap monitoring of Z-strain European corn borer (Lepidoptera:Pyralidae): Optimum pheromone blend, 
comparison of blacklight traps, and trap number requirements. Journal of Economic Entomology, 90, 449-457.

[18] Tóth, M., Csonka, É., Bartelt, R.J., Cossé, A.A., Zilkowski, B.W., Muto, S. and Mori, S. (2005) Pheromonal activity of compounds identified from male Phyllotreta cruciferae: Field tests of racemic mixtures, pure enantiomers, and combinations with allyl isothiocyanate. Journal of Chemical Ecology, 31, 2705-2720. doi:10.1007/s10886-005-7621-y
[19] Dickens, J.C. (2006) Plant volatiles moderate response to aggregation pheromone in Colorado potato beetle. Journal of Applied Entomology, 130, 26-31. doi:10.1111/j.1439-0418.2005.01014.x

[20] Martel, J.W., Alford, A.R. and Dickens, J.C. (2005). Synthetic host volatiles increase efficacy of trap cropping for management of Colorado potato beetle, Leptinotarsa decemlineata (Say). Agricultural and Forest Entomology, 7, 79-86. doi:10.1111/j.1461-9555.2005.00248.x 